\title{
Penerapan Algoritma Finite State Machine pada Game Horror 3D untuk Melestarikan Budaya Tradisional Bangsa Berbasis Android
}

\author{
Septa $^{1}$, dan Aries Saifudin ${ }^{2}$ \\ ${ }^{1,2}$ Teknik Informatika, Universitas Pamulang, Tangerang Selatan, Indonesia \\ e-mail: 1,2 \{septa.mahara79, aries.saifudin\}@gmail.com
}

\begin{abstract}
Indonesia is a country that is rich in its unique culture, but modern society is embarrassed to admit it, especially mythical culture such as the characters of native Indonesian ghosts, heirlooms, historic places that are mystical and many more. Though the myth culture is a lot of positive values that can be used as lessons. To introduce the culture of myth, it can take advantage of technological advances, one of which is games. By building an Android-based 3-dimensional horror game that adds experience about Indonesian culture. To help the animation control system with the 3-dimensional game model requires a method, one of which uses finite state machine (FSM). The advantages of this FSM are very simple, efficient, easy to develop and reliable in overcoming a wide variety of situations. From the results of the implementation and testing, it can be concluded that the game built can add to the experience of Indonesian culture based on the percentage of respondents of $77.8 \%$, and the implementation of the finite state machine method works well and according to the wishes. This can be observed when playing enemy animation games running according to certain conditions and have been running according to the design that has been made.
\end{abstract}

Keywords: Culture Myth, Game Horror, Finite State Machine

\section{Pendahuluan}

Beberapa industri kreatif yang sudah mengangkat sebuah tema horor, adakalanya mereka membuat produk yang tidak sesuai dengan tema. Di mana mereka yang telah mengangkat tema horor, mereka menambahkan unsur lain yang membuat tema horor itu menjadi tidak terlihat. Mereka setidaknya menambahkan unsur budaya dan sejarah pada karya mereka (Zihni \& Husni, 2015). Namun, sebagian masyarakat modern merasa malu untuk mengakui kebudayaan mitos Indonesia seperti karakter hantu-hantu asli Indonesia, benda-benda pusaka, tempat-tempat bersejarah yang berkesan mistis dan masih banyak lagi. Padahal, pada beberapa budaya mitos tersebut terdapat nilai-nilai positif yang dapat dijadikan sebagai pelajaran (Hendriano \& Bintoro, 2015). Pada kasus ini masih sedikit industri kreatif yang mengenalkan budaya Indonesia yang mengangkat tema horor. Maka dari itu dibutuhkan sebuah media untuk mengenalkan budaya Indonesia yang bertema horor dengan memanfaatkan kemajuan teknologi yang berkembang saat ini yaitu game.

Dahulu, game hanya sebagai media hiburan tetapi sekarang game juga dapat dijadikan sebagai media pembelajaran dan lomba oleh para professional (David, 2016). Di usia remaja maupun dewasa, hampir semuanya menyukai permainan game. Namun di antara banyak game yang ada, masih jarang game survival horror bergenre First Person Shooter (FPS) yang tersedia untuk para penggemar game (Nuruzzuha \& Hendriyanto, 2016). Teknologi dengan piranti bergerak atau mobile yang fleksibel bisa mempermudah pengguna bisa melakukan permainan di mana saja. Salah satu teknologi mobile yang banyak digunakan dan gratis adalah dengan menggunakan android (Adisusilo \& Nasution, 2014). Ada beberapa metode dalam mengontrol karakter animasi sebuah model yang dilakukan terhadap game android terutama pada desain yang memiliki tampilan 3 dimensi (3D), salah satunya adalah menggunakan algoritma Finite State Machine.

Finite State Machine (FSM) adalah pengontrol pergerakan pada suatu model game sesuai kondisi yang telah diterapkan. Penerapan algoritma FSM ini juga berguna untuk menentukan dan mendesain berbagai macam respon pada model game (Rahadian, Suyatno, \& Maharani, 2016). Kelebihan dari FSM ini adalah sederhana, efisien, dan mudah dikembangkan (Ramadijanti, Setiowati, \& Fathoni, 2015).

Tujuan dari penelitian ini adalah membuat game horor 3D berbasis android yang mengimplementasikan algoritm FSM, dimana algoritma FSM digunakan sebagai sistem cerdas, selanjutnya cerita di dalam game tersebut mengandung sebuah pengenalan tentang budaya 
dan cerita Indonesia yang mempelajari tentang beberapa lokasi atau tempat bersejarah yang ada di Indonesia.

\section{Penelitian Terkait}

Pada penelitian Haryanto dan Novianto (Haryanto \& Novianto, 2014) permasalahan yang dihadapi yaitu dalam sebuah game edukasi menimbulkan permasalahan dalam menyatukan antara belajar dan bermain. Untuk itu diatur pembelajaran yang memuat seluruh materi dalam sebuah skenario. Supaya pemain dapat merasakan pengalaman belajar yang unik. Penelitian ini menggunakan metode FSM untuk mengatur skenario game yang sesuai aksi dan kemampuan pemain. Skenario game yang berbeda yang di terapkan antar pemain dapat menimbulkan pengalaman unik yang mempengaruhi tingkat motivasi bermain dan pemahaman materi yang telah diberikan. Hasil dari penelitian ini adalah game pendidikan yang dapat menerapkan skenario adaptif.

Pada penelitian David (David, 2016) permasalahan yang dihadapi perlu adanya pengembangan mobile game terutama game bertipe horror yang menjadi favorit dikalangan gamer. Tujuan penelitian ini membuat game horror FPS android, misi game ini memecahkan teka-teki. Penelitian ini menggunakan metode pengembangan Multimedia Luther. Hasil dari penelitian ini berupa sebuah game berjudul The Dead Corridor dengan tampilan FPS 3D.

Pada penelitian Adisusilo dan Nasution (Adisusilo \& Nasution, 2014) permasalahan yang dihadapi generasi sekarang yang terkena dampak budaya barat umumnya menganggap budaya Indonesia terlihat kuno dan ketinggalan jaman, sehingga generasi enggan mengenal budaya dan sejarah Indonesia. Penelitian ini menggunakan metode FSM untuk merancang model permainan pengenalan budaya Indonesia, sehingga dengan pemodelan tersebut memungkinkan dikembangkannya komplektifitas yang lebih tinggi dalam implementasi permainan yang sesuai dengan budaya bangsa Indonesia. Hasil dari penelitian ini karakter yang diambil dari berbagai budaya dan kebudayaan bangsa bisa diimplementasikan dalam permainan berbasis android, seperti kebudayaan masa majapahit dan wayang jawa.

Pada penelitian Nuruzzuha dan Hendriyanto (Nuruzzuha \& Hendriyanto, 2016) permasalahan yang dihadapi masih jarang game survival horror bergenre FPS (First Person Shooter) yang tersedia untuk para penggemar game. Berdasarkan situs blog.agatestudio.com yang telah melakukan survei pada tahun 2012 mendapat hasil bahwa game FPS menjadi game favorit ke 3 dengan jumlah pengguna sebesar $40 \%$.

Penelitian ini menggunakan metode Software Development Life Cycle dengan model prototype. Dengan penggunaan metode ini, pengembang dan user dapat saling berinteraksi selama proses pembuatan aplikasi guna mencari solusi dari masalah yang ada. Hasil dari penelitian ini Game FPS Horror of Campus yang mengangkat cerita urban di suatu daerah telah dapat diterima dengan baik berdasarkan pengangkatan cerita urban, serta konten game yang interaktif meskipun beberapa kurang setuju dengan game yang mudah dimainkan.

Pada penelitian Bimantoro dan Haryanto (Bimantoro \& Haryanto, 2016) permasalahan yang dihadapi murid kesulitan memahami konsepkonsep akademis dikarenakan selama ini yang digunakan guru terbatas pada metode ceramah. Solusinya adalah menggunakan media game sebagai metode yang membantu pembelajaran siswa. Penelitian ini menggunakan metode FSM untuk merancang respon perilaku musuh dalam game. Hasil penelitian ini adalah metode FSM dapat membantu pembelajaran siswa untuk mengenal unsur-unsur kimia.

\section{Metode Penelitian}

Pada penelitian ini diusulkan metode finite state machine sebagai pengontrol model karakter musuh. Kelebihan dari algoritma FSM ini adalah sederhana, efisien dan mudah dikembangkan.

Penerapan FSM dalam game ini berfokus pada pengendali animasi yang ditentukan oleh berbagai syarat dan kondisi. FSM diterapkan pada pengendali animasi karakter musuh. Berikut adalah rancangan finite state machine pada karakter musuh pada Gambar 1.

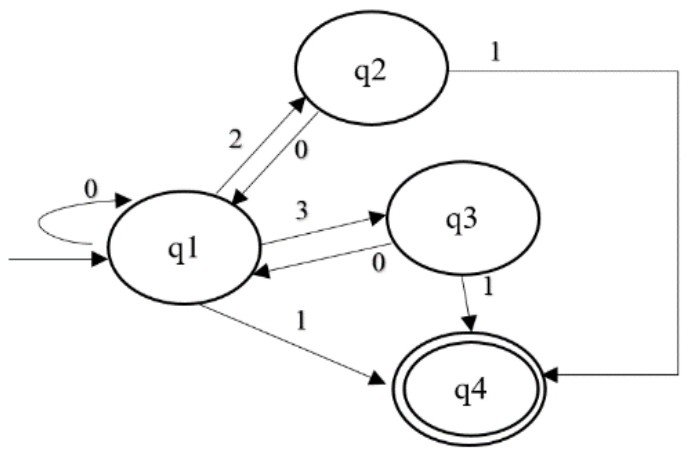

Gambar 1 Finite State Diagram Karakter Musuh

Keterangan kondisi yang ada pada Gambar 1 yaitu: $\mathrm{Q}=\{\mathrm{q} 1, \mathrm{q} 2, \mathrm{q} 3, \mathrm{q} 4, \mathrm{q} 1\}$ 


$$
\begin{aligned}
& \sum=\{0,1,2,3\} \\
& S=\mathrm{q} 1 \\
& \mathrm{~F}=\{\mathrm{q} 4\} \\
& \Delta=\{((\mathrm{q} 1,0) 0),((\mathrm{q} 1,2) \mathrm{q} 2),((\mathrm{q} 1,3) \mathrm{q} 4),((\mathrm{q} 2,0) \\
& \mathrm{q} 1),((\mathrm{q} 2,1) \mathrm{q} 4),((\mathrm{q} 3,0) \mathrm{q} 1),((\mathrm{q} 3,1) \mathrm{q} 4)\}
\end{aligned}
$$

Di mana pada pengontrol karakter musuh, Q merupakan himpunan state yang terdiri dari aksiaksi terdapat pada karakter musuh q1 mewakili keadaan idle, q2 mewakili keadaan run, q3 mewakili keadaan attack, q4 mewakili keadaan death. $\sum$ merupakan himpunan simbol masukan. Dalam hal ini jarak atau parameter adalah simbol masukan yang akan digunakan. Adapun simbol masukan itu adalah $0,1,2,3$. S adalah state awal yaitu q1 dan $\mathrm{F}$ adalah state akhir yaitu, $\{\mathrm{q} 4\}$.

$0=$ tidak ada kondisi apapun

$1=$ jika health musuh $<=0$

$2=$ jika jarak player $>=6$

$3=$ jika jarak player $<=3$

State awal adalah karakter menjalankan animasi idle. Selama tidak ada kondisi apapun state awal akan selalu diputar. Dalam posisi idle, animasi akan berubah kedalam state run jika kondisi jarak player $>=6$ dengan musuh. Jika kondisi jarak player $<=3$ dengan musuh maka akan berubah ke state attack. Jika player kabur hingga di luar jangkauan maka karakter ini akan kembali ke state awal. Jika health musuh $<=0$ maka karakter musuh akan berubah ke state death.

Perancangan game ini menggunakan analisis permodelan berorientasi objek dengan menggunakan UML (Unified Modeling Language).

\section{a. Use Case Diagram Game Horror 3D}

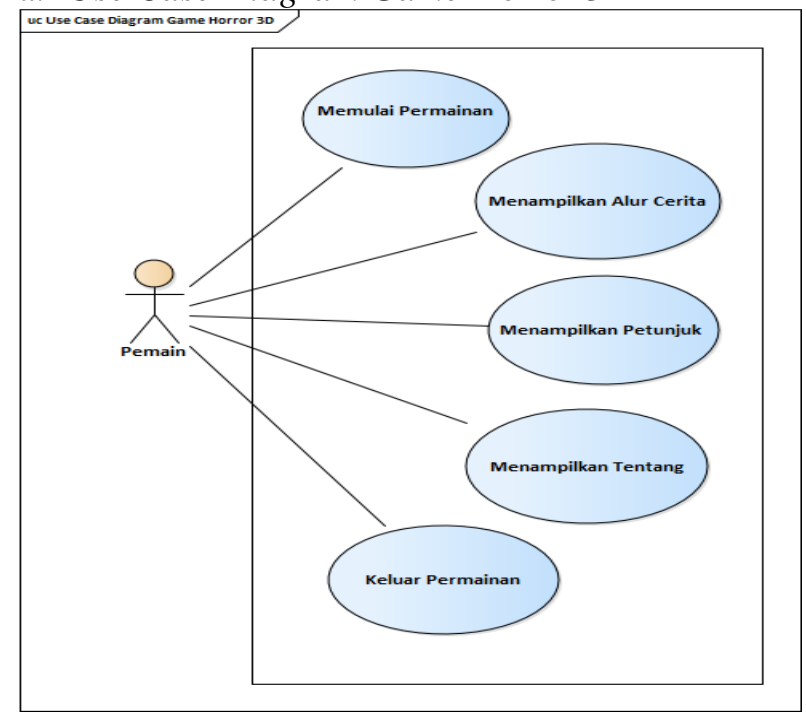

Gambar 2 Use Case Diagram Game Horror 3D
Pada Gambar 2 pemain adalah orang yang mengoperasikan game. Pemain dapat memilih salah satu menu yang ada di menu utama, terdapat 5 menu yang tampil di menu utama yaitu, memulai permainan, alur cerita, petunjuk, tentang dan keluar.

\section{b. Activity Diagram Memulai Permainan}

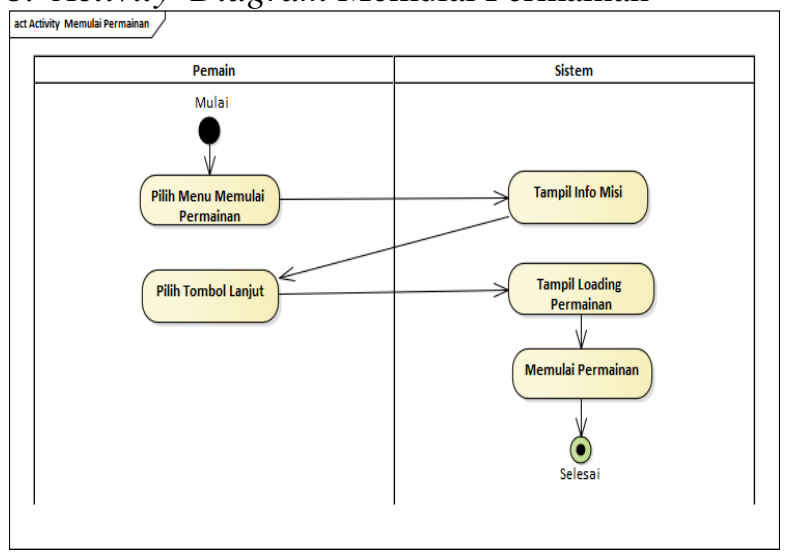

Gambar 3 Activity Diagram Memulai Permainan

Pada Gambar 3 saat pemain memilih menu memulai permainan, maka sistem akan menampilkan info misi permainan. Ketika pemain menekan tombol lanjut, maka sistem akan menampilkan loading permainan setelah itu sistem akan memulai permainan.

\section{Hasil dan Pembahasan}

Hasil dari aplikasi yang telah dibuat, yaitu game horor 3D. Berikut adalah tampilan yang ada pada game horor 3D:

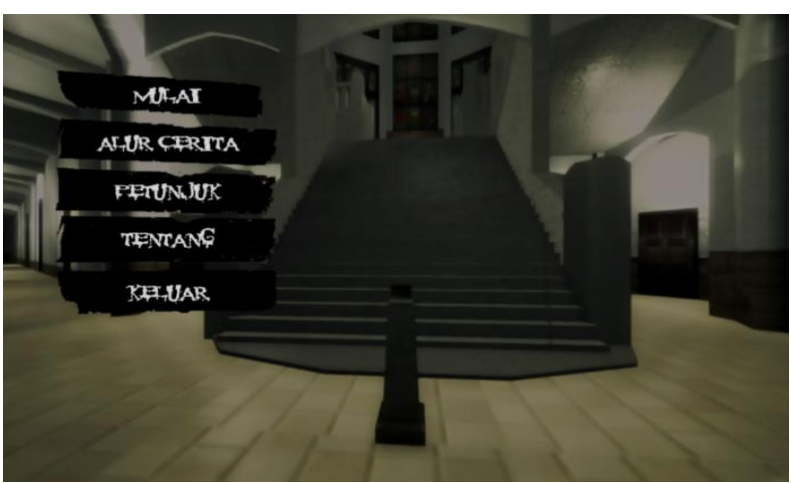

Gambar 4 Menu Utama

Pada Gambar 4 pemain dapat memilih 5 tombol menu yaitu, mulai, alur cerita, petunjuk, tentang, dan keluar. Tombol mulai untuk memulai permainan, tombol alur cerita untuk menampilkan alur cerita pada permainan, tombol petunjuk untuk menampilkan cara bermain, tombol tentang untuk menampilkan informasi pembuat game, tombol keluar untuk menutup aplikasi. 


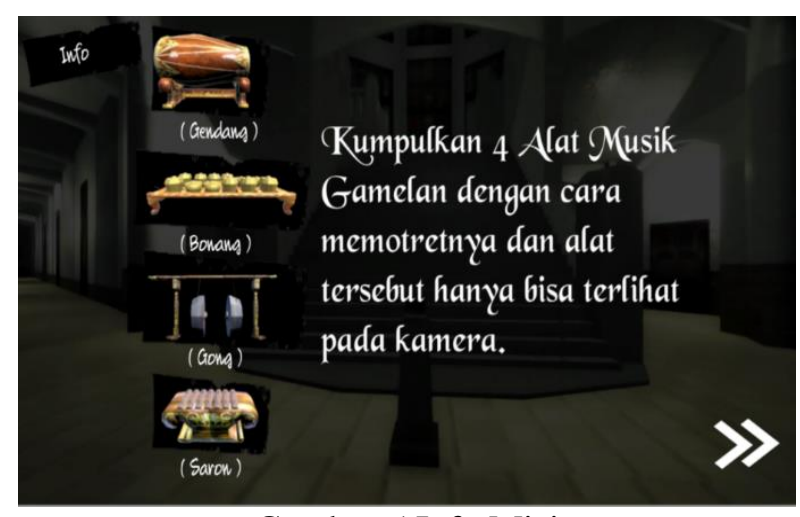

Gambar 5 Info Misi

Pada Gambar 5 berisi tentang misi yang harus dicapai dalam menyelesaikan permainan yaitu mengumpulkan 4 alat musik gamelan dengan cara memotretnya dan alat tersebut hanya bisa terlihat pada kamera dan terdapat tombol lanjut untuk menuju ke loading permainan.

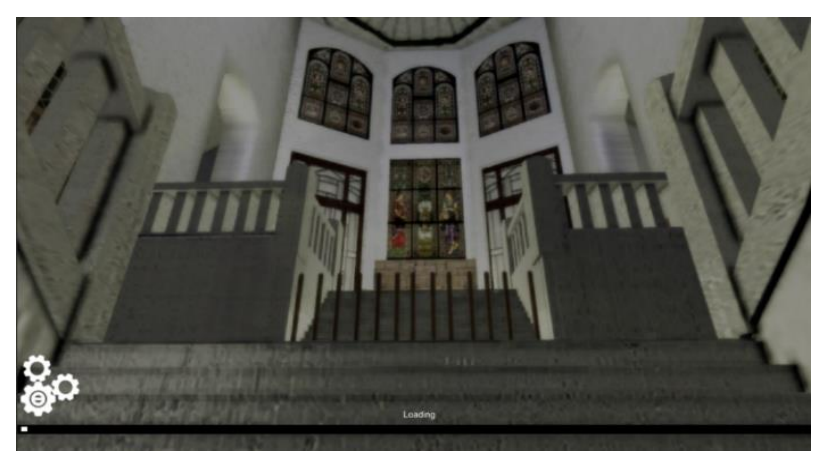

Gambar 6 Loading Permainan

Pada Gambar 6 terdapat text loading dan loading indikator. Text loading berguna untuk memberi informasi jika game sedang berada di halaman loading permainan. Fungsi loading indikator untuk memproses aset-aset yang akan digunakan pada permainan. loading indikator akan dimulai dari 0\% sampai $100 \%$ jika sudah sampai $100 \%$ maka loading permainan selesai lalu akan menuju permainan.

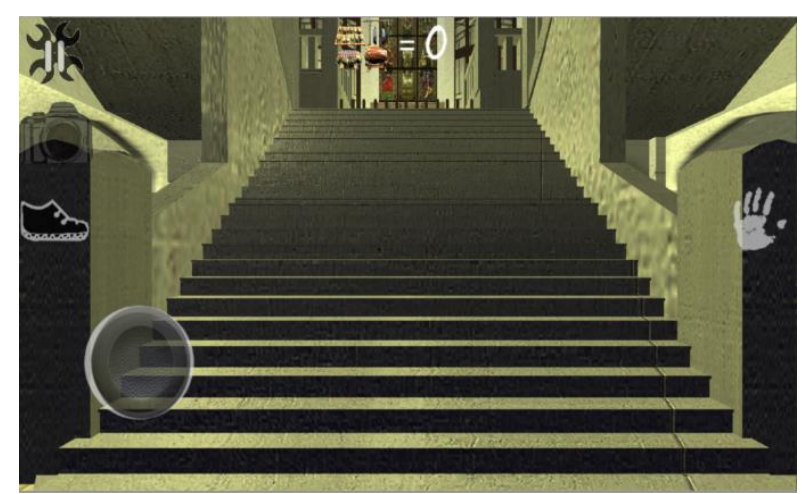

Gambar 7 Memulai Permainan
Pada Gambar 7 terdapat tombol berhenti, analog, kamera, lari dan interaksi. Pada tombol berhenti berguna untuk memberhentikan permainan, tombol kamera untuk mengaktifkan kamera yang berguna untuk melihat dan mengambil benda pada misi permainan, tombol lari untuk player dapat bergerak cepat, tombol interaksi untuk membuka pintu, tombol analog untuk menggerakan karakter pemain, pada text 0 berfungsi untuk menyatakan jika sudah mendapat objek yang dicari maka akan bertambah dan pada gambar misi adalah gambar objek yang akan dicari untuk menyelesaikan permainan.

Pengujian metode FSM yang diterapkan untuk pengendali animasi pada karakter Musuh. Pengujian dilakukan saat permainan dijalankan, menghasilkan data sebagai berikut:

Table 1 Hasil Pengujian Metode FSM

\begin{tabular}{|c|l|c|c|}
\hline \multirow{2}{*}{$\begin{array}{c}\text { Animasi } \\
\text { Musuh }\end{array}$} & \multicolumn{1}{|c|}{ Kondisi } & \multicolumn{2}{|c|}{ Keterangan } \\
\cline { 3 - 4 } Idle & $\begin{array}{l}\text { Tidak ada } \\
\text { kondisi }\end{array}$ & $\checkmark$ & - \\
\hline Run & $\begin{array}{l}\text { Jika jarak } \\
\text { player }>=6\end{array}$ & $\checkmark$ & - \\
\hline Death & $\begin{array}{l}\text { Jika health } \\
\text { musuh<=0 }\end{array}$ & $\checkmark$ & - \\
\hline Attack & $\begin{array}{l}\text { Jika jarak } \\
\text { player }<=3\end{array}$ & $\checkmark$ & - \\
\hline
\end{tabular}

Pada Table 1 diketahui jika tidak ada kondisi apapun maka animasi idle pada karakter musuh akan berjalan, jika kondisi jarak player dengan musuh $>=6$ maka animasi run akan berjalan, jika kondisi health musuh $<=0$ maka animasi death akan berjalan, dan jika jarak player dengan musuh $<=3$ maka animasi attack akan berjalan. Maka diketahui animasi musuh pada game horror 3D telah berhasil berjalan sesuai rancangan yang telah diterapkan.

\section{Kesimpulan}

Hasil implementasi dan pengujian game yang dibuat didapatkan kesimpulan bahwa game horror ini dapat menambah pengalaman tentang budaya Indonesia. Karena berdasarkan hasil pengujian kuesioner, penilaian game horror ini dapat menambah pengalaman tentang budaya Indonesia dengan presentase sebesar 77,8\%. Dari hasil implementasi metode FSM pada pengontrol model animasi pada karakter musuh berjalan dengan baik dan sesuai keinginan. Dapat diamati ketika permainan dimulai animasi pada model musuh dapat berjalan sesuai syarat dan kondisi yang telah dibuat sesuai rancangan. 


\section{Daftar Pustaka}

Adisusilo, A. K., \& Nasution, B. Y. (2014). Pengenalan Budaya Indonesia Melalui Permainan Berbasis Android. Smatika Jurnal , 1-13.

Bimantoro, T., \& Haryanto, H. (2016). Pemodelan Perilaku Musuh Menggunakan Finite State Machine (FSM) pada Game Pengenalan Unsur Kimia. Journal of Applied Intelligent System, 210-219.

David. (2016). Perancangan Game Mobile Android Bergenre Horror. Cogito Smart Journal, 167-179.

Haryanto, H., \& Novianto, S. (2014). Model Skenario Adaptif Berbasis Finite State Machine pada Game Pendidikan. Techno.com, 91-98.

Hendriano, \& Bintoro, K. (2015). Petualangan Game 2D Tentang Mitos Indonesia. eProceeding of Applied Science, 11171125.

Nuruzzuha, Y., \& Hendriyanto, R. (2016). Aplikasi Game FPS "Horror of Campus". $e$ Proceeding of Applied Science, 909-913.

Rahadian, M. F., Suyatno, A., \& Maharani, S. (2016). Penerapan Metode Finite State Machine pada Game "The Relationship". Jurnal Informatika Mulawarman, 14-22.

Ramadijanti, N., Setiowati, Y., \& Fathoni, K. (2015). Penerapan Finite State Machine Pada Perilaku Karakter. Departemen Teknik Elektro dan Teknologi Informasi, FT UGM, 30-36.

Zihni, A. I., \& Husni, M. (2015). Virtual Reality Horror Game Sieun. e-Proceeding of Applied Science, 1094-1096. 